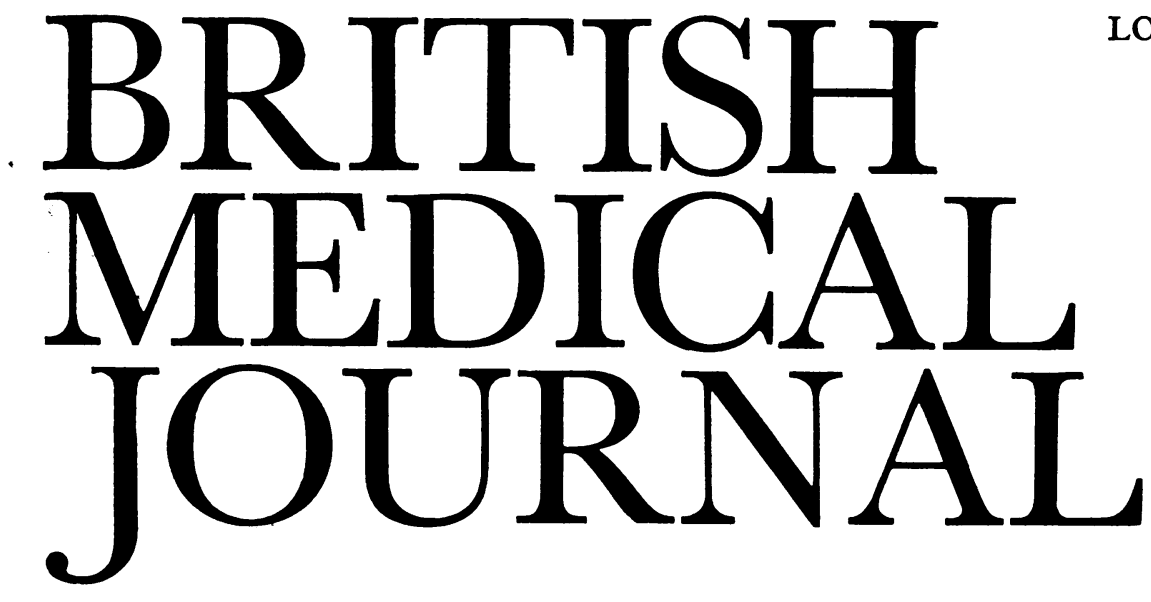

LONDON, SATURDAY 9 SEPTEMBER 1978

\title{
Health and safety at work
}

The Health and Safety at Work Act of 1974 departs from earlier legislation in several ways. Hospitals, health centres, medical schools, universities, and many others have now been added to the traditional factories, mines, and quarries as places where the employer is required to ensure the health and safety of his employees. Another important departure is the employer's duty under section 3 to conduct the undertaking so that persons other than employees are not put at risk to their health and safety - a phrase that might include patients in hospital.

While there is no doubt that medical schools and postgraduate institutes, along with universities, come under the Act and are liable to the enforcement procedures such as prohibition notices and legal proceedings, there has been some question whether the National Health Service (with its Crown status) might be exempt-at least from enforcement. The Government has recently given a firm commitment, however, that it will take the necessary action to ensure that all Crown bodies, including the NHS, do comply with the Act's provisions. ${ }^{1}$

How does the NHS measure up to the new requirements? The Health and Safety. Executive has recently completed a field study ${ }^{2}$ of working conditions in the health service. The report should not be lightly dismissed on the grounds that many of the hazards faced by medical workers are obvious and have been known for years. The comments of independent experts on, for example, the storage and use of highly flammable liquids and compressed and liquefied gases are welcome, for the medical service has much to learn about dangers of this kind. On the other hand, doctors will be less than welcoming if the Health and Safety Executive should invade the territory of clinical practice, where there are already more than enough checks. ${ }^{3}$

The report has, however, taken the disappointing line of discussing all hazards, both acknowledged and potential, without discrimination. Such an approach does not lead to a practical course of action. A contrast may be drawn with the recent Howie report ${ }^{4}$ on microbiological hazards in laboratories. In his introduction Sir James Howie acknowledged that the financial implications of the exhaustive recommendations made it unlikely that most would be implemented-and he pinpointed those hazards to be given priority. Area health authorities, faced with allocating scarce resources, need and must expect guidance on the priority to be given to dealing with the many hazards, likely and unlikely, listed by the Health and Safety Executive; and the executive must be asked to provide it. Furthermore, NHS staff have been dismayed to learn that the DHSS does not intend to provide NHS authorities with extra funds to implement the Health and Safety at Work Act. ${ }^{5} \mathrm{Mr}$ Eric Deakins, Under-secretary of State at the DHSS, told representatives of the staff side of the General Whitley Council that the cost would have to be met by economies elsewhere. Not surprisingly, the staff side have condemned this attitude and have refused to agree a circular implementing the Act in the NHS. The Government will presumably now offer its own advice to health authorities.

The field study also includes a brief discussion of occupational health services in the NHS, which are noted to be "essentially under the control of nurses." The activity (or inactivity) of the DHSS in the 10 years since the Tunbridge report draws the comment that the development of occupational health departments within the NHS to implement those recommendations "is in a transition phase." Since the report to the BMA Council by a working group under Dr P A B Raffle $^{6}$ in 1975 the Association has urged that occupational health services for the NHS should be organised without delay. ${ }^{78}$

The new report provides welcome support for the view that the largest employer of labour in the country-which spends some $70 \%$ of its revenue account on salaries and wagesshould, like other large employers, provide an occupational health service staffed by adequately trained doctors and nurses. Nevertheless, a report on health and safety should not be allowed to distort the true functions of such a service. Occupational medicine is concerned not only with the effects of work on health but also with the effects of health on work. Resettlement and rehabilitation after sickness or injury need to be provided for employees. What is known of sickness absence among NHS employees? Is the pressing problem long-term sickness absence associated with medical factors or frequent short-term sickness absence associated with social and personal factors? An occupational health service for the NHS must decide how to allocate scarce resources between tackling all the minutiae detailed by the health and safety inspectors and dealing with personnel problems affecting health and work. 
Finally, what of the suggestion that section 3 of the Health and Safety at Work Act might cover the care and treatment of patients? The report touches on the suggestion several times. A recurrent theme is that the inspectors may be interested if a patient "is injured as a result of mishandling when being lifted from a bed or trolley," "contracts sepsis as a result of surgery," "receives incorrect treatment/wrong blood or drug or wrong operation," or "suffers as a result of a professional mistake on the part of a surgeon or laboratory technician." Furthermore, supplying and administering anaesthetics or analgesic mixtures to patients are seen to pose new problems of considerable importance for the inspectors under section 3 of the Act.

While the health professions recognise the need to maintain and where necessary to raise the standards of the health and safety of those who work in the Health Service, hazards of this kind-essentially arising in a clinical context-are another matter. Inspection under a Health and Safety Act cannot be the most appropriate way to deal with risks to patients, whether caused by cross-infection, inappropriate medication, or wrong decisions. The inspectors who enforce the Act come from a background of factory inspection, while their medical colleagues in the Employment Medical Advisory Service come from occupational medicine. There is no evidence that either group has been trained, or has any special competence, to deal with these essentially clinical risks.

1 British Medical fournal, 1978, 2, 136.

2 Working Conditions in the Medical Service. London, Health and Safety Executive, 1978.

3 British Medical fournal, 1978, 2, 513.

4 British Medical fournal, 1978, 1, 871.

${ }^{5}$ Hansard, House of Commons, 13 April 1978.

- British Medical fournal, 1975, 1, 288.

${ }^{7}$ British Medical fournal, 1976, 1, 1091.

${ }^{8}$ British Medical fournal, 1976, 2, 382.

\section{Asthma in children}

Asthma never fails to generate controversy. In this tradition Speight ${ }^{1}$ has recently suggested that childhood asthma tends to be both underdiagnosed and undertreated by general practitioners. The grains of truth which he assembled are best judged alongside other grains from our present knowledge so that the difficult problems which confront the general practitioner can be seen in perspective.

Few children who have asthma remain undiagnosed until late childhood, and when recognised it turns out to be mild. Asthma is undoubtedly underdiagnosed under the age of 5 years, but that is understandable given the possibilities of confusion with other causes of chronic respiratory disease, bronchiolitis, and wheeze associated with recurrent viral infections. Many and perhaps most of these wheezing children will prove to be asthmatics, but there must often be clinical doubt: the clinical evidence is not enough to make a clear distinction. Williams and $\mathrm{McNicol}^{2}$ considered wheezy bronchitis to be part of the range of asthma. Lenney and Milner ${ }^{3}$ found that nearly all their patients over the age of 20 months had abnormal bronchial lability as indicated by a dilator response to salbutamol. Under that age, however, many infants did not respond for reasons which are not yet clear.

The clinical criteria for the diagnosis of asthma in older children are well established. In addition to the usual symptoms a chronic persistent cough, often paroxysmal, always suggests continuing stimulation by allergens. When the diagnosis is in doubt (and because parents and doctors may be reluctant to use the word "asthma") referral to a respiratory unit is advisable for tests of abnormal bronchial lability based on exercise or histamine provocation. ${ }^{45}$ Tests at a younger age are more difficult but possible. ${ }^{6}$

Is asthma being undertreated? In fact, the nation probably spends enough on its drug bill for asthmatic children, yet it does not get value for money. Why? When a drug fails a frequent response is to add another. The parent comes to hospital with a plastic bag containing a pharmaceutical arsenal of drugs and says, "Nothing works." Bronchodilator inhalers have often been used with regularity and increasing frequency (as in the bad old days of the 1960s). These drugs should be reserved for treating specific attacks: if frequent use becomes necessary (several times daily) that is an indication for further investigation. By contrast, sodium cromoglycate and topical steroids have often been taken "when attacks occur" or irregularly, whereas they should be taken regularly as prophylactics, irrespective of the occurrence of attacks. If an oral steroid is found in the bag it has usually been overused. If it is not there it has been shunned as too dangerous to use at all. An occasional short course of steroids to treat an acute attack is harmless and effective at any age, and the drug may be given intramuscularly or intravenously when there is urgency. But, again, should such courses become a regular necessity, the time has come to refer the patient for a specialist opinion. Antibiotics are always to be found in the bag: yet they have no specific effect on asthma or on the viral infections which so often precipitate attacks under the age of 5 years.

Patients are not, then, being undertreated, but drugs are often used incorrectly and, more important, too much is demanded of them. There is a limit to what chemotherapy can achieve, and if the exposure to antigens (at home, in school, at relatives' or friends' houses) is too great, then the drug in use will fail and another one will be added or substituted. The parents with the plastic bag often come from a home containing pets, yet when tackled they hasten to explain that they have always had pets and the child never reacts to them. There is much confusion on this point. Peckham and Butler ${ }^{7}$ state that "a great deal can now be done to prevent chronic respiratory damage resulting from harmful allergens; for example, regular or intermittent medication with antispasmodics or disodium cromoglycate." There is no evidence that drugs will protect in this way, whereas removing or minimising contact with allergens will undoubtedly help. The absence of any history and negative results of skin tests are no excuse for introducing a cat into the home of an allergic child, exposing him to the risk of extending his existing range of sensitivity and thus reducing the chances of chemotherapeutic control of the disease. This is one way in which mild asthma becomes severe, and it may be a factor determining whether the child will "grow out of his asthma." Peckham and Butler? found little evidence of remission in their survey: half of their children with a history of asthma at 7 were still suffering attacks four years later. A fall to less than half could hardly be expected by 11 , for the usual age for remission is $10-15$ years. Nevertheless, undoubtedly remission is much less frequent in the $20 \%$ of severe asthmatics with a broad range of sensitivity to allergens. No asthmatic child should live with animals in the same house and precautions against dust mites should always be rigorous. Such precautions are probably particularly important in the early years when the disease is first diagnosed and the range of sensitivity is still limited. 